Article

\title{
Social-Psychological Determinants of Serbian Tourists' Choice of Green Rural Hotels
}

\author{
Aleksandar Grubor, Nikola Milicevic * and Nenad Djokic \\ Department of Trade, Marketing and Logistics, Faculty of Economics in Subotica, University of Novi Sad, \\ 24000 Subotica, Serbia; agrubor@ef.uns.ac.rs (A.G.); djokicn@ef.uns.ac.rs (N.D.) \\ * Correspondence: milicevic.nikola@ef.uns.ac.rs; Tel.: +381-21-485-2933
}

Received: 30 September 2019; Accepted: 18 November 2019; Published: 26 November 2019

\begin{abstract}
The significance of green rural tourism for sustainable development is widely recognized. In addition, a number of researches attempt to explain the green choice among tourists. Hereby, different theoretical approaches are used. The dynamic approach to the Theory of Planned Behavior (TPB) is implemented in this study. The approach considers that the influence of different elements of TPB (attitudes, subjective norms, perceived behavioral control) on intention to visit green rural hotels is tested in the context of different phases in behavior change of the respondents (pre-decision, pre-action, action). According to the authors' knowledge, this is the first implementation of the dynamic approach to the TPB in understanding green rural choice. During data analysis, multigroup structural equation modelling (SEM) was used. The results indicate that the existence and the strength of the influences of the elements of TPB are different in different phases of behavior change. Managerial implications for the studied market (Serbia) are also provided within the paper.
\end{abstract}

Keywords: sustainable development; rural tourism; green hotels; theory of planned behavior; behavior change; market segmentation

\section{Introduction}

Tourism represents a great strategy for encouraging and improving economic development, not only in developing, but in developed countries as well [1]. It made up $9.8 \%$ of global Gross Domestic Product (GDP) and contributed to the global economy with \$7.61 trillion USD in 2016 [1]. The analysis of the World Travel and Tourism Council (WTTC), which included 184 countries, has shown that the tourism sector generated 284 million workplaces, meaning that 1 out of 11 workplaces in the world comes from the tourism sector [2]. The ways in which its development affects other sectors (such as forestry, food processing, agriculture, livestock raising, fishing, and handicrafts) can improve the entire community's well-being [3]. Moreover, under the influence of several factors, including life dynamics, the increasing progress and higher knowledge level, people's desire and possibility to travel and discover will only increase in future [2]. This can be related to the prediction from the World Tourism Organization (WTO), according to which 1.8 billion people will be engaged in tourism by 2030 [1].

Tourism development does not bypass rural areas either. In contrast to urban areas, which are more utilitarian and materialistic, the countryside represents a strong evocation of a way of life and is usually observed "as a better physical and social world" [4] (p. 1). Rural tourism has a long history in most Western countries and there is written evidence related to the increased interest of middle and higher classes in visiting rural areas, dating back to the 19th century [5]. In Germany, paid holidays for civil servants and white-collar workers were organized more than 100 years ago [6]. They were spent in the countryside, near cities, in inexpensive privately let rooms or smaller hotels, usually in the 
hillier areas. Since that period, rural tourism, as a new type of tourism developing in Europe, has been satisfying the demands of people who want to get out of the cities and enjoy the quiet countryside [7].

Considering the explanation of rural tourism, "it can be broadly defined as tourism which takes place in rural areas" [8] (p. 47). In relation to this definition, previously mentioned authors raise the question about the term rural, which may differ among countries and cultures. For that matter, certain common characteristics, such as a small portion of land under buildings and low population densities can be used [8]. When it comes to the distinction between rural and urban areas, the former should be characterized by four main qualities [4] (p. 3):

- relatively lower level of physical densities related to people, activities, and buildings;

- lower level of cultural and social heterogeneity;

- lower level of economic diversity;

- comparative physical apartness from general political, economic, and social networks.

In order to accurately define rural areas, it can be referred [9] to the methodology commonly applied by the Eurostat and the OECD (The Organization for Economic Co-operation and Development), based on which "rural area, or rural population, are defined as an area, or population, of local communities/municipalities, with density of less than 100 inhabitants per 1 square kilometer" (p. 264). The additional distinctiveness lies in people's views and images of the countryside, which are different from those of the city and are based on two interrelated dimensions (personal responses to the countryside and its popular social representations) [4].

By drawing tourists to rural areas, this type of tourism has become a relevant factor in rural development, strengthening not only rural, but urban areas' profits, as well [7]. In rural areas, tourism can also bring certain positive sociocultural effects, including development of the local economy and its independence, reinvestment in cultural resources, the increase of respect for local communities, reinforcement of cultural traditions and the increase of toleration and compromise among different cultures [10]. However, bearing in mind that rural tourism depends on numerous factors, such as cultural and natural resources, interpretative facilities, infrastructure and tourist offer in terms of accommodation, services, and goods, its inappropriate regulation can lead to threats to culture, social structures, and the physical environment [11]. Thus, special attention should be dedicated to its managing and development.

Considering rural tourism and development, there can be identified three different viewpoints [10]. From the first one, tourism is employed as a strategy for rural development, whereby, new strategies should be created in order to renew or change rural areas threatened by the decline of agriculture and the decay of villages. For this purpose, complementary activities could be developed, addressing their human and natural resources. From the second viewpoint, tourism is considered as a policy related to renewing rural zones, by reducing dependency on agriculture and turning to new business opportunities. The last (third) point of view refers to rural tourism as an important asset of sustainable development. Bearing in mind its direct relationships with nature, rural culture, and values, and thus its potential environmental and cultural effects, the analysis of rural tourism in regard to sustainability has been drawing the attention of many researches [10].

The concept of sustainable development became known after the Brundtland Report from 1987, in which it was described as satisfying the present needs without influencing the future generations' capacity to fulfil their own needs [2]. The paradigm of sustainability, based on three different aspects (economic, social, and environmental), has been used in various areas of knowledge and life [12], affecting the tourism industry as well [13]. The first ideas of sustainable tourism appeared under the pressure of visitors on countryside communities [4] in Central Europe, among French-, Italian-, and German-speaking areas [14]. This was most notably in the Alpine mountain regions, due to the increase of summer vacationing and intensive winter sports. Since then, many initiatives and projects within sustainable tourism have been related to the countryside [4]. Therefore, sustainable tourism, contrary to artificial tourism theatre intended for exploitation, can proffer the authentic countryside lifestyle, 
i.e., "real scenario, where life is realistic and nature can be preserved by the same local inhabitants and hosts at the same time" [12] (p. 557).

Following the definition of the United Nations, sustainable tourism represents a type of tourism which pays full attention to its current and future social, economic, and environmental effects, taking into account the needs of visitors, the environment, the industry, and host communities [1]. A similar explanation is given by the World Tourism Organization, according to which models of sustainable tourism must be focused on the needs of current tourists and the recipient region, as well as on the protection of resources, all in order to ensure future opportunities [15]. Regarding the definition of sustainable tourism development, there can be stressed a view that tourism development should be in line with the principles of sustainable development and the local economy, respecting the natural environment permanence and local community's good, from both an ethical and social aspect [13]. There are three main goals related to the sustainable development of the tourism sector: ecological, economic, and social [13], whereby all three types of interests need to be balanced, even in the case when said balance is not provided or automatic [15]. In order to ensure the mentioned balance, in the context of sustainable tourism, the focus should be on [16]:

- the optimum usage of natural resources, sustaining crucial ecological processes, and preserving biodiversity and natural heritage,

- respecting the host communities' sociocultural authenticity, protection of traditional values and cultural heritage, and tolerance among different cultures,

- providing sustainable long-term business and socioeconomic utilities, ensuring stable employment level, income opportunities, and welfare for local communities, and reduction of poverty,

- sustaining a high level of tourist satisfaction, spreading awareness of sustainability, and promotion of this type of tourism.

Although there is a great potential of rural tourism to foster economic development and local economy diversification, considering its relations and respect to the natural and social environments, there are also some potentially negative consequences associated to environmental and social effects in rural tourism, which depend on several factors such as the number of tourist arrivals, environmental fragility, local culture steadiness, etc. [15]. Having that in mind, an option is to aim for green tourism, which presents "an important component of sustainable tourism" [17] (p. 66) and can be, besides resort tourism, "a form of rural tourism" [18] (p. 135). To this can be added that "one of the more important recent innovations in the tourist sector" that gained "increasing prominence" [19] (p. 300) in previous years, especially at some markets, are green hotels. In the literature, there is often offered the explanation of the Green Hotels Association, according to which a green hotel is "an environmental friendly lodging property that institutes and follows ecologically sound programs/practices (e.g., water and energy savings, reduction of solid waste, and cost saving) to help protect our planet" [20] (p. 325). Although from previous explanations it can be seen that green hotels do not have to be necessarily correlated to rural areas, they can also be associated to a green form of rural tourism.

A number of researches have used the Theory of Planned Behavior (TPB) in explaining green hotel choices. Furthermore, that theory was implemented wider-for predicting different green choices [21]: organic food and products, recycled products, green toys, eco-car, green-certified products, etc. The theory originally includes [22] attitudes towards behavior (formed in the relationship between beliefs and evaluation of beliefs), subjective norms (social pressure on people to behave (or not) in a certain way), and perceived behavioral control (perception of own ability to perform certain behavior). Hereby, those variables predict intention to perform behavior. Furthermore, that variable, together with perceived behavioral control, influence actual behavior.

There can be identified several manners of the use of the Theory of Planned Behavior in the explanation of green hotel choices. On one hand, there is implementing solely the elements of original theory. On the other hand, there is extending the theory with additional variables, often from other theoretical approaches (since there can also be noticed the use of other theories (e.g., the Model of 
Goal-directed Behavior or the Values-Beliefs-Norms (VBN) theory [23]) in the sustainable tourism field). Furthermore, some methodological aspects should be considered in TPB implementation-for example, the dynamic approach [24], or asymmetrical modelling [25].

Having all previously explained in mind, the main goal of this paper is to implement the dynamic approach to the Theory of Planned Behavior for explaining green hotel choices within rural tourism offer. According to the authors' knowledge, this is the first such implementation of TPB in predicting intention to visit green hotels, not only in the context of rural tourism, but in general as well. Besides elaborating basic issues regarding rural tourism, green tourism, green hotels, sustainable development, and their mutual relation, this paper provides a review of previous implementations of TPB in green hotels choice. Furthermore, the results of the primary research conducted in Serbia are also presented.

\section{Literature Review}

In recent years, in accordance with environmental concerns and cost reductions, the number of green hotels is increasing [26]. In addition to the business sector, green hotels have become the object of attention in the scientific field as well. Hereby, there are a number of studies which refer to the examination of customers' intention and behavior related to visiting green hotels. This field of interest is of special importance, especially bearing in mind that, despite great attention and publicity dedicated to environmentalism, it still has a low priority for customers [27].

A study conducted in the U.S. [20] used the variables from TPB-attitude, subjective norm, and perceived behavioral control (affected by behavioral, normative, and control beliefs, respectively, as well as evaluations of those beliefs) - to explain intention to visit a green hotel. The model showed appropriate fit (better in comparison to using some of the elements in the context of the Theory of Reasoned Action), which was additionally improved when adding the influence of subjective norm on attitude. Although the research included moderation analysis as well (the comparison of the strength of described influences between customers that actively practice ecofriendly activities and those who do not perform it in such a manner), there were no significant results from it.

A research from Taiwan [28] extended explanation of intention to visit a green hotel by adding past behavior to independent variables from ТРB. Furthermore, the influence of that variable on intention to visit a green hotel was hypothesized to be both direct and indirect (through attitude, subjective norm, and perceived behavioral control). Finally, authors expected that influence of subjective norm and perceived behavioral control on intention to visit a green hotel is also mediated by attitude. The results confirmed the significance of all the relations except the influence of perceived behavioral control on attitude.

Another study from Taiwan [19] extended TPB with altruism. Hereby, the authors showed that intention to visit a green hotel is directly influenced by attitude, subjective norm, perceived behavioral control, and altruism, whereas there were also indirect influences on that variable from subjective norm (through attitude) and altruism (through attitude, and perceived behavioral control).

Environmental education presents a variable by which TPB was also expanded in a research in Taiwan [29]. Hereby, it is expected that it influences intention to visit green hotels both directly, and mediated by behavioral beliefs determining attitude, normative beliefs determining subjective norm, and control beliefs determining perceived behavioral control. While the authors succeeded in documenting the influence of appropriate beliefs on elements of TPB, the influence of those elements on visit intention, as well as indirect influence of environmental education, they did not confirm the direct influence of environmental education on visit intention.

Intention to visit a green hotel is once again examined in a study in Taiwan [30], but this time by adding perceived moral obligation to its antecedents together with attitude toward visiting a green hotel, subjective norms, and perceived behavioral control. Furthermore, all those variables mediate the influence of environmental concern on intention to visit a green hotel. Authors confirm all listed influences to be significant. 
The extension of TPB with additional variables in a study conducted in the U.S. [31] showed better fit with the data and greater explained percentage of the variance when explaining revisit intentions of a green hotel. Besides the influence of the elements from TPB-attitude, subjective norm, and perceived behavioral control (caused by behavioral, normative, and control beliefs, respectively) —on revisit intention, that variable is also being influenced by customer satisfaction, overall image, and frequency of past behavior. Furthermore, a variable service quality is modeled as antecedent for both customer satisfaction and attitudes, while there is also an influence of subjective norm on attitude. Not only did the results regarding the extended model show superior predictive power, but also, all the hypothesized relations were statistically significant.

A research in India [32] expanded TPB in predicting green hotel visit intention with two additional constructs-moral reflectiveness and conscientiousness. Hereby, the added variables influence the dependent variable, both directly and indirectly (through the variable attitude). The results showed that all the hypotheses derived from the described model were supported.

When it comes to extending TPB with several (or all) elements from other theoretical approaches, there is evidence [33] that its combination with VBN theory provides superior prediction power in comparison to the separate usage of TPB, VBN, or the Norm Activation Model. That research was created to understand intentions regarding green lodging. It was performed on the sample of respondents from the U.S. Firstly, there were expected positive influences of attitudes towards the behavior, subjective norms, and perceived behavioral control on behavioral intention, with the moderating role of non-green alternatives' attractiveness in all those relations. The model also included variable adverse consequences for valued objects. It was influenced by biospheric value mediated by ecological worldview. Furthermore, it affected all independent variables from TPB, as well as behavioral intention mediated by, in a following order, ascribed responsibility and obligation to take pro-environmental actions. Obligation to take pro-environmental actions is also influenced by subjective norms, while mediation (regarding non-green alternatives' attractiveness) is studied considering the influence of that variable on dependent variables as well. The results confirmed the significance of all presented influences, whereas all of them were positive. Hereby, the strongest influence on behavioral intention can be assigned to variables' adverse consequences for valued objects, subjective norms, and sense of obligation to take pro-environmental actions. Furthermore, the influences of independent variables from TPB as well as of obligation to take pro-environmental actions were stronger when non-green alternatives' attractiveness was lower.

In a research conducted in India [34], TPB was combined with the Attitude-Behavior-Context $(\mathrm{ABC})$ Theory to explain travelers' intentions to stay in green hotels. Besides psychological factors from TPB, the model includes contextual factors: biospheric value, green trust, and willingness to pay a premium. Hereby, perceived behavioral control, subjective norm, and willingness to pay a premium affect dependent variable only directly. Attitude and green trust influence dependent variable both directly and indirectly (through willingness to pay a premium in the first and willingness to pay a premium and all psychological variables in the second case). Biospheric value determines dependent variable only indirectly (through willingness to pay a premium, green trust, and all psychological variables). The results confirmed most of the hypothesized relations with the exception of the influence of biospheric value on willingness to pay a premium and subjective norm, the effect of subjective norm on intention to stay in green hotels, and the influence of the attitude on willingness to pay a premium.

In a study which attempted to explain the choice of nature-based tourism destinations in Taiwan [35], TPB is combined with the technology acceptance model, Value-Belief-Norm theory, and social identity theory. Besides all the relations taken from the original TPB, the model includes perceived ecotourism usefulness (from the technology acceptance model), biospheric value (from the Value-Belief-Norm theory), and ecotourism self-identity (from the social identity theory) as direct antecedents of environmental attitude, and indirect antecedents of ecotourism behavioral intention and ecotourism behavior. Furthermore, ecotourism self-identity also influences subjective norms directly and ecotourism behavioral intention and ecotourism behavior indirectly, while biospheric value effects 
ecotourism behavior directly. All hypothesized relations were confirmed except the existence of the influence of ecotourism self-identity on environmental attitude. Furthermore, the integrated model was shown to be superior in comparison to the use of the single models.

A research conducted in the UK [36] considers the elements of TPB within the stimulus-organism-response framework, together with elements of the norm-activation theory, and social identity theory. Hereby, the authors consider the influence of green hotel attributes (presented as a higher-order formative construct consisting of five reflective first-order dimensions: customer benefit, energy efficiency, recycling policy, water efficiency, and green landscape) through personal route and social route. In the first case, the influence of those attributes on attitude toward green hotels, intention to stay at green hotels, and willingness to pay a premium is mediated by the construct identification with the green hotel. In the second case, the mediator of the influence of green hotel attributes on attitude toward green hotels, intention to stay at green hotels, and willingness to pay a premium is the construct trust toward green hotels. Furthermore, controlling for social norms, personal norms strengthen the effects of green hotel attributes on both mediators. Analogously, controlling for personal norms, social norms strengthen the effects of those attributes on identification with the green hotel and trust toward green hotels. The results confirmed the existence of all the relations except the positive interaction effects between social norms and green hotel attributes on identification with the green hotel and trust toward green hotels.

When it comes to methodological issues regarding TPB implementation, a configurational model can be proposed as an alternative for the extension, decomposition, and merging of that theoretical approach [25]. The research considers the influence of attitude, subjective norm, and perceived behavioral control (predictors $X$ ) in formulating the behavioral intentions of green hotel guests' - continued use and recommendations (outcomes $\mathrm{Y}$ ) by symmetrical model and asymmetrical model. That was performed in a manner that "the assumption in symmetrical thinking is that high or low scores of predictor $(\mathrm{X})$ link with high or low scores of outcome $(\mathrm{Y})$, whereas in an asymmetrical relationship, high/low scores of $X$ do not necessarily connect with those of $Y$. " The results of symmetrical model (SEM - structural equation modelling) showed all independent variables to be significant predictors of continued use, while only attitude and subjective norm in the case of recommendations. The results of the asymmetrical model for high scores on continued intention to use green hotels and recommend them are similar. Two propositions were given regarding those outcomes. Firstly, the positive attitudes towards the behavior are sufficient for achieving those goals. Secondly, there can be used a combination of high level of perceived behavioral control and low level of subjective norms. For low scores on continued intention to use green hotels, two combinations can be defined: firstly, low perceived behavioral control and high attitude towards the behavior, and secondly, low levels of attitude towards the behavior, and subjective norms, and high level of perceived behavioral control. For low scores on intention to recommend, there can also be defined two combinations: firstly, low level of attitude towards the behavior, and secondly, low levels of subjective norms, and perceived behavioral control. Finally, the results of the necessary condition analyses indicated that, without an attitude, intention to continue using as well as to recommend green hotels cannot be accomplished.

In certain studies, in which a configurational model was applied, tourists' behavioral intentions were analyzed in the context of, among others, demographic characteristics. Thus, demographic variables were used in combinations with host and accommodation place attributes in order to describe disabled tourists' behavioral outcomes in relation to p2p accommodations [37]. They were also included in an asymmetrical analysis related to the recommendation intention of canal boat tour participants [38], as well as in a configurational model developed for "predicting residents' support for tourism development (RSTD)" [39].

Although the TPB model was often used when analyzing customers' pro-environmental intentions and behavior, one of the model's shortcomings is related to "its relatively static perspective on behavior change" [24] (p. 213). Bearing in mind that behavioral change can be best seen as "a person's transition through a temporally ordered sequence of qualitatively different stages" [40] (p. 
69), the understanding of customer behavior can be improved by implementing the dynamic approach in the model [24]. Thus, four different phases, each with a specific task, can be distinguished [40]: pre-decisional (turning certain wishes into obliging goals), pre-actional (forming a behavioral intention), actional (the implementation of intention) and post-actional (maintenance of new behavior).

TPB is implemented in the context of the dynamic approach for understanding moving into energy-efficient homes [24]. The main foundation of the approach used within that research is the difference of influences of different elements of TPB (hereby, they consider attitudes, social norms, perceived behavioral control, personal norms, and emotions as well) depending on the phase in the change of the behavior (pre-decision, pre-action, action) in which the respondent is.

Having all previously stated in mind, and especially that, according to the authors' knowledge, the dynamic approach was not previously implemented regarding green hotel choice, the following model is formulated-Figure 1.

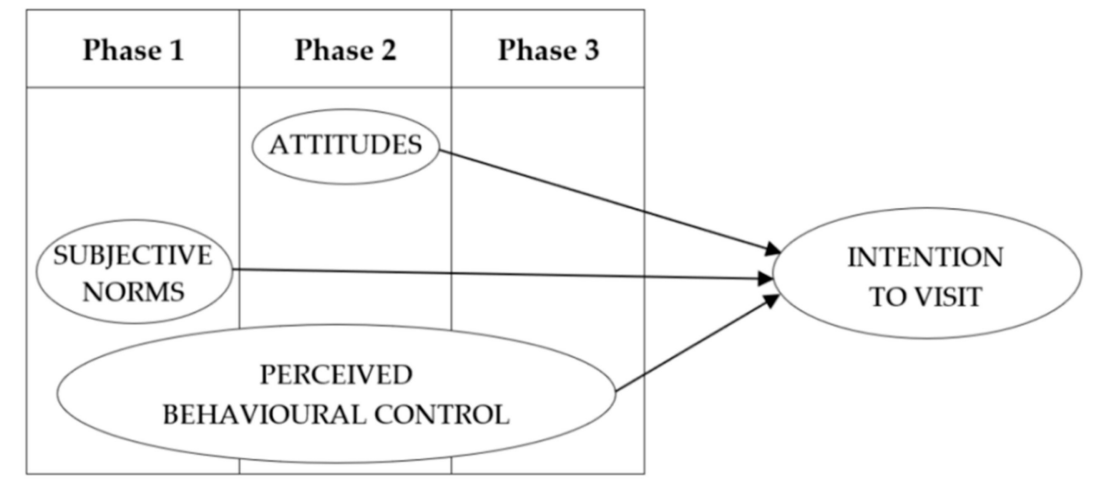

Figure 1. Conceptual model.

Within this research, the following hypotheses are set:

H1. Intention to visit a green rural hotel is in the first phase of tourists' behavioral change (pre-decision) influenced by subjective norms and perceived behavioral control.

H2. Intention to visit a green rural hotel is in the second phase of tourists' behavioral change (pre-action) influenced by attitudes and perceived behavioral control.

H3. Intention to visit a green rural hotel is in the third phase of tourists' behavioral change (action) influenced by perceived behavioral control.

H4. Together with the increase in the phase of tourists' behavioral change, increases the influence of perceived behavioral control on intention to visit a green rural hotel.

\section{Materials and Methods}

The questionnaire consisted of three parts. The first part was related to sociodemographic characteristics of respondents: gender, age, education, and marital status. The second part of the questionnaire was referring to identifying the phase in behavior change. It was performed by adapting formulations from previous research [24] to the topic of this research. Hereby, the respondents were offered to choose one of the following options: "So far, I've never thought about staying at a rural green hotel when traveling," "I have considered staying at a rural green hotel when traveling. However, I haven't put this plan into practice yet," "For my last travel I have stayed at a rural green hotel. It is my firm intention to do this in the future," or "For me it is a given to stay at a rural green hotel when traveling." According to the choice of one of the selected options, respondents were segmented into four phases of behavior change: pre-decision, pre-action, action, and post-action phase, respectively. The third part of the questionnaire was related to measuring variables from TPB (on a five-point Likert scale). That was performed by adapting items from previous research [32]. 
Personal communication with respondents from the Republic of Serbia was performed. The convenience sampling method was implemented. In order to try to interview the average user of tourist services, the respondents were approached at several of the largest Serbian towns near famous shopping centers during all seven days of one week. The precondition for a person to become a respondent was that he/she was using hotel services during 12 months before the interview. The questionnaire was either read to the respondent and he/she provided answers to the interviewer, or the respondent personally filled in the questionnaire in the presence of the interviewer. The questionnaires with no answer regarding phase in behavior change, or on more than one item referring to latent variables from TPB (43 in total), were excluded. In the case of missing only one item for some of the variables from TPB, it was filled in by a mean of other items belonging to the same latent variable. Data were processed in 2019. It included analysis of 289 answers.

The sample consisted of $48.8 \%$ males and $51.2 \%$ females. Hereby, the average respondent was 37.05 years old (standard deviation 10.21). When it comes to education, $45.3 \%$ of the respondents had finished secondary school, $7.6 \%$ of the respondents were students, and $47.1 \%$ had finished college or faculty. As for marital status, $63.3 \%$ of the respondents were married and $36.7 \%$ were single. Furthermore, $23.5 \%$ of the respondents were in the first, $41.9 \%$ in the second, $27.7 \%$ in the third, and $6.9 \%$ in the fourth phase of behavior change.

When analyzing the influences of TPB elements on intention to visit green rural hotels in different phases, multigroup structural equation modelling was performed. Hereby, the respondents in one of the first three phases were taken into account-as in [24]. Prior to performing multigroup SEM, the questionnaire was tested.

\section{Results}

\subsection{Testing the Questionnaire}

As all four constructs from TPB are reflective, individual indicator reliability, internal consistency reliability, convergent validity, and discriminant validity were examined [41]. For analyzing indicator reliability, standardized loading for each indicator was checked. As expected, they were higher than 0.7 (Table 1).

Table 1. Quality criteria of the reflective constructs.

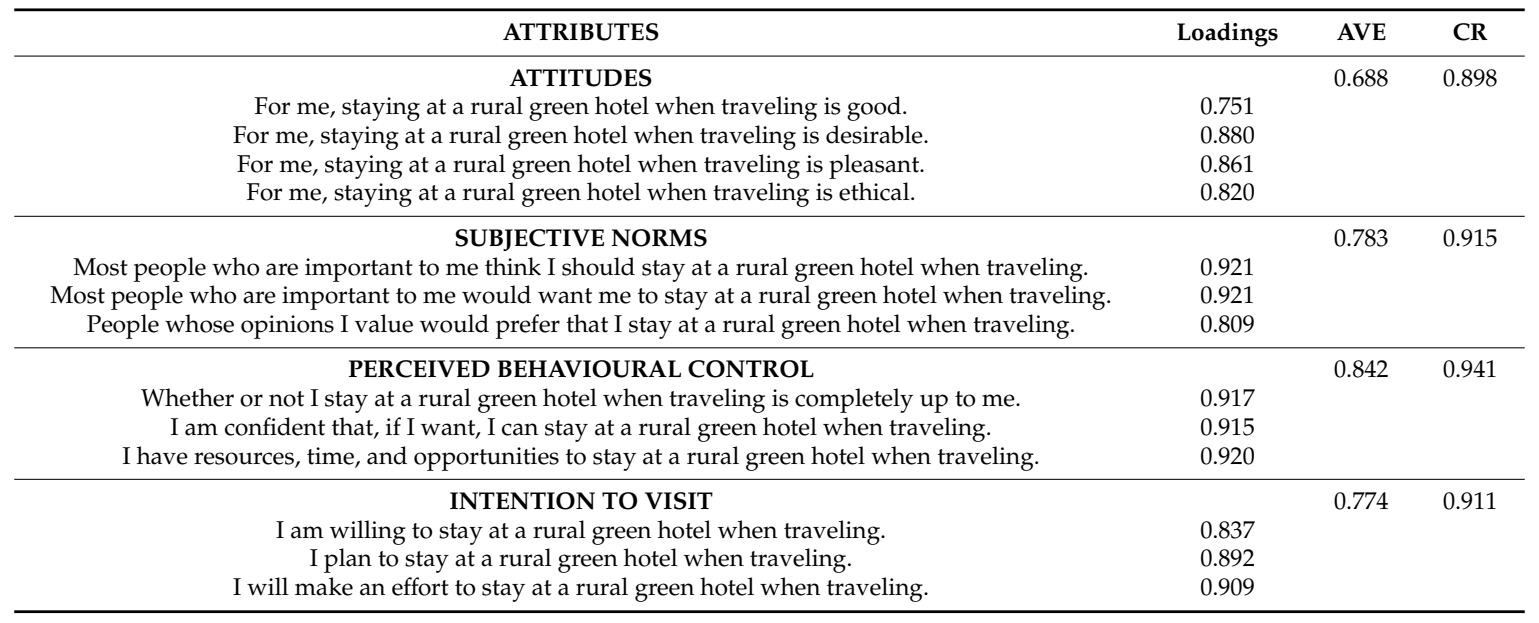

Satisfactory levels were obtained in the case of internal consistency reliability and convergent validity, as well. Hereby, the values of CR (composite reliability) and AVE (average variance extracted) were above 0.7 and 0.5 , respectively $[42,43]$.

For assessing discriminant validity, the Fornell-Larcker criterion was applied (Table 2). 
Table 2. Discriminant validity assessment: Fornell-Larcker criterion.

\begin{tabular}{ccccc}
\hline & Attitudes & Subjective Norms & Perceived Behavioral Control & Intention to Visit \\
\hline Attitudes & $\mathbf{0 . 8 2 9}$ & & & \\
Subjective norms & 0.121 & $\mathbf{0 . 8 8 5}$ & $\mathbf{0 . 9 1 7}$ & \\
Perceived behavioral control & 0.481 & 0.053 & 0.426 & $\mathbf{0 . 8 8 0}$ \\
Intention to visit & 0.474 & 0.242 & \\
\hline
\end{tabular}

Hereby, each construct's square root of AVE is higher than its correlations with other constructs [41], which confirms discriminant validity.

Having in mind that all variance inflation factor (VIF) values for all latent variables are lower than 3.3, "the model can be considered free of common method bias" [44] (p. 7).

\subsection{Testing the Hypotheses}

The effects of independent variables on Intention to visit green rural hotel have been analyzed by using PLS-SEM path coefficients. Table 3 presents their values for the entire model and for each of three phases as well. Furthermore, the $R^{2}$ value equaled 0.311 .

Table 3. Path coefficients.

\begin{tabular}{ccccc}
\hline & \multicolumn{4}{c}{ Intention to Visit } \\
\hline & Phase 1 & Phase 2 & Phase 3 & General \\
\hline Attitudes & 0.080 & $0.643^{*}$ & -0.006 & $0.327^{*}$ \\
Subjective norms & $0.787^{*}$ & 0.152 & -0.041 & $0.189^{*}$ \\
Perceived behavioral control & 0.098 & -0.011 & $0.891^{*}$ & $0.259^{*}$ \\
\hline${ }^{*} \mathrm{p}<0.05$ & & & \\
\hline
\end{tabular}

At the level of the entire model, significant positive effects have been recorded for all three independent constructs, attitudes, subjective norms, and perceived behavioral control $(0.327,0.189$, and 0.259 , respectively). When it comes to phases, attitudes construct had a significant positive effect only in the second phase (0.643), subjective norms in the first (0.787) and perceived behavioral control in the third phase (0.891). Differences in path coefficients between phases have been tested by the implementation of Multi-group Analysis (MGA)-Table 4.

Table 4. Multi-group analysis (MGA)—coefficients differences.

\begin{tabular}{cccc}
\hline & \multicolumn{3}{c}{ Intention to Visit } \\
\hline & | Phase1-Phase2 | & | Phase1-Phase3 | & | Phase2-Phase3 | \\
\hline Attitudes & $0.563^{*}$ & 0.086 & $0.649 *$ \\
Subjective norms & $0.635^{*}$ & $0.828^{*}$ & 0.193 \\
Perceived behavioral control & 0.109 & $0.793 *$ & $0.902 *$ \\
\hline$* \mathrm{p}<0.05$ or $\mathrm{p}>0.95$ & & \\
\hline
\end{tabular}

Hereby, in relation to attitudes construct, the path coefficient in phase 2 is significantly higher than coefficients in phases 1 and 3 . In the case of subjective norms, the coefficient in phase 1 is significantly higher than coefficients in phases 2 and 3. Finally, in relation to perceived behavioral control, the path coefficient in phase 3 is significantly higher than coefficients in phases 1 and 2 .

\section{Discussion and Conclusions}

From the research conducted within this paper, important implications can be derived for both theory and practice. When it comes to the theoretical contribution, it should be stressed that, 
according to the authors' knowledge, this research is the first dynamic approach to TPB in the context of green rural hotels. That presents the key contribution of this paper. The special significance of the topic is that it belongs to one of the two identified methodological issues regarding the TPB in recent studies-dynamic approach and asymmetrical modelling.

The results show that when the model is performed for all the respondents, the influence of each of the independent variables (attitudes, subjective norms, perceived behavioral control) on dependent variables is statistically significant. That is in accordance with almost all previous researches that implement SEM in general. Moderation analysis is rarely present $[20,36]$ or fails to provide significant differences in those researches [20]. However, when moderation analysis is performed within this research, based on the phase in behavior change (pre-decision, pre-action, action), it can be concluded that the significant influence of all the variables is not present in each of the phases. In the first phase, there is a significant influence of only subjective norms on intention to visit green rural hotels; in the second phase, solely attitudes significantly affect the dependent variable; while in the third phase, perceived behavioral control is the only significant predictor of green rural hotels choice.

In the previous context can be discussed the confirmation of hypotheses. It should be noted that the first hypothesis is partially confirmed since intention to visit a green rural hotel is in the first phase of tourists' behavioral change (pre-decision), influenced by subjective norms, but not by perceived behavioral control. A similar situation can be observed regarding the second hypothesis, as well. Hereby, intention to visit a green rural hotel is in the second phase of tourists' behavioral change (pre-action), influenced by attitudes, but it is not affected by perceived behavioral control. The third hypothesis is confirmed since intention to visit a green rural hotel is in the third phase of tourists' behavioral change (action), influenced by perceived behavioral control. The fourth hypothesis is partially confirmed. When comparing the third phase of behavior change to previous phases, the influence of perceived behavioral control on intention to visit a green rural hotel is the strongest and statistically significant. However, in previous phases, influences of that variable are neither statistically significant, nor is there an increase in the second phase in comparison to the first.

The difference from the expectations regarding influence of independent variables is noticed in previous research as well [24]. From the results of this research, it can be concluded that, when a person has never thought to stay at a rural green hotel when traveling, the greatest influence on intention to visit such a hotel is the perception of opinion of people who are considered important. Furthermore, for people who have considered staying at a rural green hotel when traveling, but have not put that plan into practice yet, the greatest influence is the one of their own attitudes. Finally, for respondents that are already in the phase of action, the only importance is the perception of their own ability to perform such behavior. It was hypothesized that such influence would be important in previous phases as well, but the results did not support it. Two explanations can be given regarding such results. Firstly, because of the underdeveloped offer of such hotels in domestic conditions, that factor might become important to respondents only when they face the actual visit to them. Within the research, the questions were formulated in general, so it cannot be examined whether respondents in the action phase are referring to the domestic offer of green rural hotels or from such hotels abroad. Furthermore, the decision regarding visiting hotels is usually made much faster than, for example, the decision to buy a hybrid vehicle or to move into an energy-efficient home. That can be an additional explanation why the perception of own ability to perform a behavior does not become important before the action phase.

The practical recommendations can be given for different segments obtained in this research based on the phase in behavior change. All these recommendations can be of special importance to sustainability; as it is proven within the paper, the significance of rural tourism and green hotels in that context. For people who have never thought to stay at a rural green hotel when traveling, influencing persons can be relied on. Additional research is necessary to discover persons who might be considered as relevant for a great part of respondents from that segment and, if using massive communication, it might be chosen to cooperate with some of the celebrities. Hereby, attention should be dedicated to those people who like to travel and act socially responsible. They can be engaged in 
promotional campaigns, in which the emphasis should be on rural areas and their natural beauties. For this purpose, social networks, especially Instagram, could be of great help. For the segment of respondents who have considered staying at a rural green hotel when traveling, but have not put that plan into practice yet, it is of the greatest importance to influence their positive beliefs about performing such actions as well as their evaluations. A campaign containing information that would help in accomplishing that goal would be recommendable. Thus, it may include some information related to advantages of rural areas, such as natural and healthy environment, less noise, clean air, and domestic food. Besides presenting the countryside as a place for rest and relaxation, attention should be dedicated to the ethical aspect as well. Hereby, potential tourists should be informed about the sustainability concept, i.e., environmental protection and all benefits for the social community in rural areas. When considering the segment of respondents in the action phase, it is important to increase their perception of their ability to stay at green rural hotels. In addition to their consideration of the resources and time needed to visit rural green hotels, support should also be provided to the supply side of the market. Hereby, it would be useful to provide them with information about offers of such hotels in domestic conditions, about the best routes to approach them, and the necessary time and costs when performing such actions. For example, popular TV shows presenting routes to popular destinations for summer vacations could also be used to transmit previously listed information.

Future researches could use larger and more representative samples. Additional moderations considering whether the destination is domestic or foreign can be included. Rural tourism offer can be considered without focusing only on green hotels. Finally, asymmetrical modelling could be implemented on the data of this research as well, in order to obtain an even deeper understanding of TPB functioning. Beside elements of TPB, that analysis could also integrate demographic data.

Author Contributions: All of the authors formulated goals of the research and interpreted available literature; conducting and analyzing research was performed by N.M. and N.D., while implications were developed by A.G.

Funding: This research received no external funding

Conflicts of Interest: The authors declare no conflict of interest.

\section{References}

1. Shafiee, S.; Ghatari, A.R.; Hasanzadeh, A.; Jahanyan, S. Developing a model for sustainable smart tourism destinations: A systematic review. Tour. Manag. Perspect. 2019, 31, 287-300. [CrossRef]

2. Butnaru, G.I.; Haller, A.P. Perspective of Sustainable Rural Tourism in the United Kingdom of Great Britain and Northern Ireland (UK): Comparative Study of $\beta$ and $\sigma$ Convergence in the Economic Development Regions. Sustainability 2017, 9, 525. [CrossRef]

3. Su, M.M.; Wall, G.; Wang, Y.; Jina, M. Livelihood sustainability in a rural tourism destination-Hetu Town, Anhui Province, China. Tour. Manag. 2019, 71, 272-281. [CrossRef]

4. Bramwell, B. Rural tourism and sustainable rural tourism. J. Sustain. Tour. 1994, 2, 1-6. [CrossRef]

5. Perales, R.M.Y. Rural tourism in Spain. Ann. Tour. Res. 2002, 29, 1101-1110. [CrossRef]

6. Oppermann, M. Rural tourism in southern Germany. Ann. Tour. Res. 1996, 23, 86-102. [CrossRef]

7. Campón-Cerro, A.M.; Hernández-Mogollón, J.M.; Alves, H. Sustainable improvement of competitiveness in rural tourism destinations: The quest for tourist loyalty in Spain. J. Destin. Mark. Manag. 2017, 6, 252-266. [CrossRef]

8. Ghaderi, Z.; Henderson, J.C. Sustainable rural tourism in Iran: A perspective from Hawraman Village. Tour. Manag. Perspect. 2012, 2-3, 47-54. [CrossRef]

9. Šimková, E. Strategic approaches to rural tourism and sustainable development of rural areas. Agric. Econ. Czech 2007, 53, 263-270. [CrossRef]

10. Noori, K.; Zand, F. The Role of Rural Tourism in Rural Sustainable Development According to the SWOT Method (Case Study: Kermanshah Province villages). Int. Res. J. Appl. Basic Sci. 2013, 4, 2620-2625.

11. Cawley, M.; Gillmor, D.A. Integrated rural tourism: Concepts and Practice. Ann. Tour. Res. 2008, 35, 316-337. [CrossRef] 
12. Fons, M.V.S.; Fierro, J.A.M.; Patiño, M.G. Rural tourism: A sustainable alternative. Appl. Energy 2011, 88, 551-557. [CrossRef]

13. Kapera, I. Sustainable tourism development efforts by local governments in Poland. Sustain. Cities Soc. 2018, 40, 581-588. [CrossRef]

14. Lane, B. Will sustainable tourism research be sustainable in the future? An opinion piece. Tour. Manag. Perspect. 2018, 25, 161-164. [CrossRef]

15. Martínez, J.M.G.; Martín, J.M.M.; Fernández, J.A.S.; Mogorrón-Guerrero, H. An analysis of the stability of rural tourism as a desired condition for sustainable tourism. J. Bus. Res. 2019, 100, 165-174. [CrossRef]

16. Podovac, M.; Jovanović Tončev, M. The importance of sustainable rural tourism development in Serbia. In Proceedings of the Sinteza 2016-International Scientific Conference on ICT and E-Business Related Research, Belgrade, Serbia, 22 April 2016.

17. Furqan, A.; Mat Som, A.P.; Hussin, R. Promoting Green tourism for future sustainability. Theor. Empir. Res. Urban Manag. 2010, 8, 64-74.

18. Meler, M.; Ham, M. Green marketing for green tourism. In Proceedings of the 21st Biennial International Congress Tourism \& Hospitality Industry 2012 New Trends in Tourism and Hospitality Management, Opatija, Croatia, 3-5 May 2012.

19. Teng, Y.-M.; Wu, K.-S.; Liu, H.-H. Integrating Altruism and the Theory of Planned Behavior to Predict Patronage Intention of a Green Hotel. J. Hosp. Tour. Res. 2013, 39, 299-315. [CrossRef]

20. Han, H.; Hsu, L.-T.J.; Sheu, C. Application of the theory of planned behavior to green hotel choice: Testing the effect of environmental friendly activities. Tour. Manag. 2010, 31, 325-334. [CrossRef]

21. Maichum, K.; Parichatnon, S.; Peng, K.-C. Application of the Extended Theory of Planned Behavior Model to Investigate Purchase Intention of Green Products among Thai Consumers. Sustainability 2016, 8, 1077. [CrossRef]

22. Ajzen, I. The theory of planned behavior. Organ. Behav. Hum. Decis. Process. 1991, 50, 179-211. [CrossRef]

23. Passafaro, P. Attitudes and Tourists' Sustainable Behavior: An Overview of the Literature and Discussion of Some Theoretical and Methodological Issues. J. Travel Res. 2019, 0047287519851171. [CrossRef]

24. Schaffner, D.; Ohnmacht, T.; Weibel, C.; Mahrer, M. Moving into energy-efficient homes: A dynamic approach to understanding residents' decision-making. Build. Environ. 2017, 123, 211-222. [CrossRef]

25. Olya, H.G.T.; Bagheri, P.; Tümer, M. Decoding behavioural responses of green hotel guests. Int. J. Contemp. Hosp. Manag. 2019, 31, 2509-2525. [CrossRef]

26. Wang, S.; Wang, J.; Wang, Y.; Yan, J.; Li, J. Environmental knowledge and consumers' intentions to visit green hotels: The mediating role of consumption values. J. Travel Tour. Mark. 2018, 35, 1261-1271. [CrossRef]

27. Nimri, R.; Patiar, A.; Kensbock, S.; Jin, X. Consumers' intention to stay in green hotels in Australia: Theorization and implications. J. Hosp. Tour. Res. 2019, 20,1-20. [CrossRef]

28. Wu, K.-S.; Teng, Y.-M. Applying the extended theory of planned behavior to predict the intention of visiting a green hotel. Afr. J. Bus. Manag. 2011, 5, 7579-7587. [CrossRef]

29. Chang, L.-H.; Tsai, C.-H.; Yeh, S.-S. Evaluation of Green Hotel Guests' Behavioral Intention. Adv. Hosp. Leis. 2014, 10, 75-89. [CrossRef]

30. Chen, M.-F.; Tung, P.-J. Developing an extended Theory of Planned Behavior model to predict consumers' intention to visit green hotels. Int. J. Hosp. Manag. 2014, 36, 221-230. [CrossRef]

31. Han, H.; Kim, Y. An investigation of green hotel customers' decision formation: Developing an extended model of the theory of planned behavior. Int. J. Hosp. Manag. 2010, 29, 659-668. [CrossRef]

32. Verma, V.K.; Chandra, B. An application of theory of planned behavior to predict young Indian consumers' green hotel visit intention. J. Clean. Prod. 2018, 172, 1152-1162. [CrossRef]

33. Han, H. Travelers' pro-environmental behavior in a green lodging context: Converging value-belief-norm theory and the theory of planned behavior. Tour. Manag. 2015, 47, 164-177. [CrossRef]

34. Yadav, R.; Balaji, M.S.; Jebarajakirthy, C. How psychological and contextual factors contribute to travelers' propensity to choose green hotels? Int. J. Hosp. Manag. 2019, 77, 385-395. [CrossRef]

35. Lee, T.H.; Jan, F.-H. Ecotourism Behavior of Nature-Based Tourists: An Integrative Framework. J. Travel Res. 2017, 57, 792-810. [CrossRef]

36. Balaji, M.S.; Jiang, Y.; Jha, S. Green hotel adoption: A personal choice or social pressure? Int. J. Contemp. Hosp. Manag. 2019, 31, 3287-3305. [CrossRef] 
37. Olya, H.G.T.; Altinay, Z.G.; Altinay, F.A.; Altinay, M. Behavioral intentions of disabled tourists for the use of peer-to-peer accommodations. Int. J. Contemp. Hosp. Manag. 2018, 30, 436-454. [CrossRef]

38. Mehran, J.; Olya, H.G.T. Canal boat tourism: Application of complexity theory. J. Retail. Consum. Serv. 2020, 53, 101954. [CrossRef]

39. Olya, H.G.T.; Gavilyan, Y. Configurational Models to Predict Residents' Support for Tourism Development. J. Travel Res. 2016, 56, 893-912. [CrossRef]

40. Bamberg, S. Applying the stage model of self-regulated behavioral change in a car use reduction intervention. J. Environ. Psychol. 2013, 33, 68-75. [CrossRef]

41. Hair, J.; Sarstedt, M.; Ringle, C.; Mena, J. An Assessment of the Use of Partial Least Squares Structural Equation Modeling in Marketing Research. J. Acad. Mark. Sci. 2012, 40, 414-433. [CrossRef]

42. Hair, J.; Ringle, C.; Sarstedt, M. Partial Least Squares Structural Equation Modeling: Rigorous Applications, Better Results and Higher Acceptance. Long Range Plan. 2013, 46, 1-12. [CrossRef]

43. Becker, J.M.; Klein, K.; Wetzels, M. Hierarchical Latent Variable Models in PLS-SEM: Guidelines for Using Reflective-Formative Type Models. Long Range Plan. 2012, 45, 359-394. [CrossRef]

44. Kock, N. Common method bias in PLS-SEM: A full collinearity assessment approach. Int. J. E-Collab. 2015, 11, 1-10. [CrossRef]

(C) 2019 by the authors. Licensee MDPI, Basel, Switzerland. This article is an open access article distributed under the terms and conditions of the Creative Commons Attribution (CC BY) license (http://creativecommons.org/licenses/by/4.0/). 